\title{
A parsimonious model of longitudinal stream DOC patterns based on groundwater inputs and in-stream uptake
}

\author{
Stefan W Ploum ${ }^{1}$, Anna Lupon ${ }^{4}$, Jason A Leach ${ }^{2,3}$, Lenka Kuglerová ${ }^{1}$, Hjalmar Laudon ${ }^{1}$ \\ $5 \quad{ }^{1}$ Department of Forest Ecology and Management, Swedish University of Agricultural Sciences, Umeå, Sweden \\ ${ }^{2}$ Natural Resources Canada, Canadian Forest Service, Sault Ste. Marie, ON, Canada \\ ${ }^{3}$ Environment and Life Sciences Graduate Program, Trent University, Peterborough, ON, Canada \\ ${ }^{4}$ Integrative Freshwater Ecology Group, Centre for Advanced Studies of Blanes (CEAB-CSIC), Blanes, Spain
}

Correspondence to: Stefan W Ploum (swploum@gmail.com)

\begin{abstract}
The supply of terrestrial dissolved organic carbon (DOC) to aquatic ecosystems affects local in-stream processes and downstream transport of DOC in the fluvial network. However, we have an incomplete understanding on how terrestrial DOC

15 inputs alter longitudinal variations of DOC concentration along headwater stream reaches because groundwater discharge, groundwater DOC concentration and in-stream DOC uptake vary at relatively short spatial and temporal scales. In the riparian zone, the convergence of subsurface flow paths can facilitate the inflow of terrestrial DOC from large upslope contributing areas to narrow sections of the stream. We refer to these areas of flow path convergence as discrete riparian inflow points (DRIPs). In this study, we ask how longitudinal patterns of stream DOC concentrations are affected by DRIPs, as they are

20 major inputs of terrestrial DOC and important locations for in-stream processes. We used a mixing model to simulate stream DOC concentrations along a $1.5 \mathrm{~km}$ headwater reach for fifteen sampling campaigns with flow conditions ranging from droughts to floods. Four sets of model scenarios were used to compare different representations of hydrology (distributed inputs of DRIPs vs diffuse groundwater inflow), and in-stream processes (passive transport vs in-stream biological uptake). Results showed that under medium (10-50 l/s) and high flow conditions ( $>50 \mathrm{l} / \mathrm{s})$, accounting for lateral groundwater inputs from DRIPs improved simulations of stream DOC concentrations along the reach. Moreover, in-stream biological uptake improved simulations across low to medium flow conditions $(<50 \mathrm{l} / \mathrm{s})$. Only during an experimental drought, longitudinal patterns of stream DOC concentration were simulated best using diffuse groundwater inflow and passive transport scenarios. These results show that the role of hydrology and in-stream processes on modulating downstream DOC exports varies over time. Importantly, we demonstrate that accounting for preferential groundwater inputs to the stream is needed to capture

30 longitudinal dynamics in mobilization and in-stream uptake of terrestrial DOC. The dominant role of DRIPs in these transport and reaction mechanisms suggests that consideration of DRIPs can improve stream biogeochemistry frameworks and help inform management of near-stream areas that exert a large influence on stream conditions.
\end{abstract}




\section{Introduction}

Running waters play a critical role in the global carbon (C) cycle because they transport dissolved organic carbon (DOC) from lands to oceans (Cole et al., 2007). Accounting for stream DOC fluxes within stream networks can be valuable for understanding net in-stream C retention (Alexander et al., 2007; Bernal et al., 2018) and catchment-integrated evasion of C (Wallin et al., 2013), as well as for assessing and managing the brownification of large water bodies (Kritzberg et al., 2020). Across fluvial networks, headwater and high-order river segments have different controls of $\mathrm{C}$ dynamics. In headwaters, terrestrial source-transport mechanisms are considered dominant drivers of DOC dynamics (Creed et al., 2015). The organization of flow paths to riparian zones (RZ) (Jencso et al., 2010; McGlynn and McDonnell, 2003; Ploum et al., 2020), riparian wetness regimes (Vidon, 2017), and local differences in soil organic carbon stocks (Grabs et al., 2012) are major controls of the spatiotemporal variability of terrestrial DOC fluxes to streams. Further, recent studies have shown that headwaters can have a reactive role as well, which can reduce downstream supply of DOC (Bernal et al., 2018; Hotchkiss et al., 2015). Mineralization by biota is a major removal mechanism of terrestrial DOC, in addition to abiotic processes such as adsorption, flocculation, and photooxidation (Mineau et al., 2016). Since the upstream supply influences downstream DOC dynamics, the entire stream network relies on terrestrial DOC sources and fluxes from RZ to headwaters (Raymond et al., 2016). Therefore, it is important to understand where and when RZs hydrologically connect to headwaters, and what effect this connection has on headwaters stream biogeochemistry (Casas-Ruiz et al., 2017).

50

To integrate the supply of terrestrial DOC fluxes and removal in aquatic ecosystems, we need to combine source-transport hydrochemical and in-stream C spiraling frameworks ( $\mathrm{Li}$ et al., 2020). While there are hydrochemical frameworks that integrate spatial heterogeneity of terrestrial DOC fluxes to streams (Seibert et al., 2009), they are mostly suitable during high flow conditions, when stream DOC dynamics are dominated by source-transport mechanisms, and in-stream uptake processes

55 are less significant (Raymond et al., 2016). By contrast, in-stream processes are mostly measured during low flows and within reaches with no lateral inputs (Mineau et al., 2016), and therefore, little is known about the role of in-stream biota on controlling DOC fluxes during storms or snow melt periods (Talbot et al., 2018; Wollheim et al., 2018). Moreover, the few quantitative biogeochemical frameworks that consider both source-transport and in-stream processing often rely on a sparsely distributed gauging stations, which do not fully capture the spatiotemporal variability of DOC dynamics within the fluvial network (Futter et al., 2007). A major influence on local stream DOC dynamics that is not captured by gauging stations is the spatial distribution of groundwater discharge (Briggs and Hare, 2018). Discrete riparian inflow points (DRIPs) convey substantial fluxes of DOC from large upslope contributing areas to narrow sections of the stream (Ploum et al., 2020). Subsequently the labile DOC that DRIPs convey to headwater streams leads to in-stream uptake directly downstream of DRIPs (Lupon et al., 2019). Depending on physical stream conditions and local microbial communities (Berggren et al., 2009; Kothawala et al., 2015; Wollheim et

65 al., 2015), this means that DRIPs are important conveyors of terrestrial DOC to streams, but also potential hotspots of instream DOC uptake.

To represent local evasion of $\mathrm{C}$ from streams to the atmosphere in $\mathrm{C}$ budgets, it is important to consider landscape features such as DRIPs (Rocher-Ros et al., 2019). To identify and characterize the groundwater supply from DRIPs to streams, there is a growing body of research that combines field-based methods with digital elevation models, and remote sensing approaches (Antonelli et al., 2020; Barclay et al., 2020; Briggs et al., 2019; Leach et al., 2017; Lidberg et al., 2019; Rosenberry et al., 2016; Selker et al., 2006). However, to quantify the supply of terrestrial DOC from DRIPs to stream networks and to consider subsequent in-stream uptake, it is important to characterize the spatial variability in groundwater chemistry as well. This remains an ongoing challenge because groundwater chemistry is highly variable in space and time (Kiewiet et al., 2019), and groundwater dynamics often need to be extrapolated from a relative small number of observations (Rinderer et al., 2019). As such, the way groundwater and streams are currently monitored does not facilitate a systematic consideration of source- 
transport mechanisms and in-stream reactions that are associated with discrete inputs of groundwater, such as DRIPs. To represent DRIPs and their associated effects on stream DOC dynamics, it is important to understand what happens with stream DOC concentrations between monitoring stations, and to understand what the influence is of DRIPs on longitudinal stream DOC dynamics.

In this study, we integrate source-transport mechanisms and in-stream uptake in a model framework, by considering DRIPs as the primary driver of both hydrological and biogeochemical processes that influence patterns of stream DOC concentrations. We used a mixing model to simulate stream DOC concentrations along a $1.5 \mathrm{~km}$ headwater reach, for fifteen sampling campaigns with flow conditions ranging from droughts to floods. With this modelling approach, our objective was to disentangle the control of terrestrial DOC inputs and in-stream DOC uptake on longitudinal stream DOC concentrations during different flow conditions. In different model scenarios, we accounted for two types of transport mechanisms: 1) assuming uniform, diffuse inflow of groundwater along the reach and 2) by assuming groundwater inflow relative to upslope contributing area (UCA). These two assumptions were than combined either with the assumption that the stream is a passive pipe, or with the assumption that in-stream DOC uptake takes place directly downstream of DRIPs.

\section{Methods}

\subsection{Study area}

We conducted our study in the Krycklan catchment in northern Sweden $\left(64^{\circ} 14^{\prime} \mathrm{N}, 19^{\circ} 46^{\prime} \mathrm{E}\right)$, along a $1.5 \mathrm{~km}$ stream segment located between the gauging stations C5 and C6 (Fig. 1) (Laudon et al., 2013). The gauging station C5 is the outlet of lake Stortjärn (4.2 ha), with a catchment area of 65 ha. The gauging station $\mathrm{C} 6$ is situated $1.5 \mathrm{~km}$ downstream, and has a catchment area of 110 ha. The catchment consists of pine-dominated forest, mostly underlain by post-glacial till soil (72\%). Iron podzols and thin soils can be found in the upland areas, and in the RZ the shallow subsurface $(<1.2$ meter $)$ is dominated by peat.

For the period $1981-2010$, the average temperature was $1.8^{\circ} \mathrm{C}$ and the average annual precipitation in Krycklan was 614 $\mathrm{mm}$, of which 35-50\% fell as snow (Laudon and Ottosson Löfvenius, 2016; Laudon et al., 2013). Recently, it has been reported that winter and fall temperatures are increasing, and that snow cover is decreasing (Laudon et al., 2021). On average, approximately $50 \%$ of the annual precipitation translates to streamflow. The hydrological regime at gauging stations $\mathrm{C} 5$ and C6 is dominated by the annual snowmelt peak, occurring around May (100-200 1/s), but at C5 peak flows are dampened by the lake (Leach and Laudon, 2019). In summer and autumn, low flows dominate (5-10 1/s), but are alternated with medium to high flows (25-75 1/s) as a response to rain events. During the winter and early spring, the stream is snow and ice covered with flows around 1-2 1/s. At C5, streamflow is mostly driven by lake level variations as a response to water contributed from the surrounding mire complex. As a result, peak flow events are dampened and recession limbs decrease slowly (Fig. S1). The downstream effect of the lake is a dominant aspect of the discharge and chemistry at C6 (Leach and Laudon, 2019). At C6, discharge can respond much faster to hydrological events compared to $\mathrm{C} 5$ and is characterized by steep rising limbs (Ploum

110 et al., 2018). This hydrological response is typically a result of rapid increases of shallow groundwater tables in the RZ, enabling periods of flow through highly conducting organic soil layers in the upper decimetres of the soil profile (Ledesma et al., 2015). The lateral inputs from the RZ are dominated by discrete riparian inflow points (DRIPs), which route $60 \%$ of the upslope contributing areas to $5 \%$ of the stream length (Leach et al., 2017). At DRIPs, flow paths from the upland converge in the RZ, which leads to near-surface groundwater levels and organic-rich groundwater chemistry (Ploum et al., 2020). 


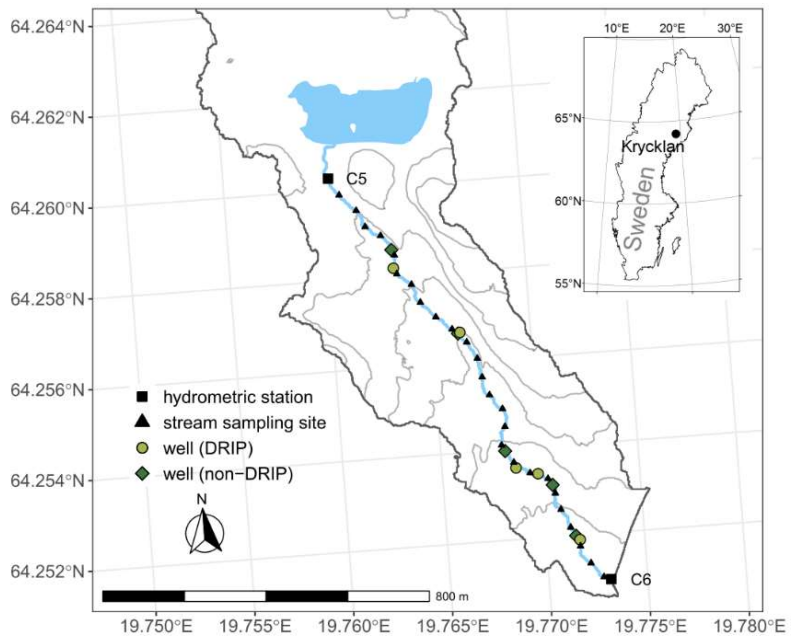

Figure 1 The Stortjärnsbacken subcatchment in Krycklan, Sweden. The stream segment starts at the outlet of lake Stortjärn (gauging station C5), and ends at the downstream gauging station C6. Stream sampling sites at approximately 50 meter increments are indicated with triangles. Light green circles (DRIPs) and dark green diamonds (non-DRIPs) represent groundwater wells along the reach. At DRIPs, flow paths converge in the riparian zone.

\subsection{Field measurements and laboratory analysis}

Field measurements were collected between May 2017 and May 2019. In total, we conducted 15 sampling campaigns with different streamflow conditions, which ranged from drought conditions to peak flows (Fig. S1). Ten sampling campaigns were centred around the snowmelt periods of 2017-2019, and five around a lake damming experiment in August 2017. In this experiment, the upstream lake was blocked, and after a period of artificial drought a series of controlled flows were released using a pump (Gómez-Gener et al., 2020).

For each sampling campaign, stream water was collected along the stream segment at approximately 50 meter intervals over 1200 meters, dividing the stream into 25 reaches (Lupon et al., 2019). Riparian groundwater was sampled from a paired well network setup, which included pairs of DRIP and non-DRIP wells (Ploum et al., 2020). The fully screened, PVC wells (30 $\mathrm{mm}$ diameter) were positioned 1-5 $\mathrm{m}$ from the stream edge, and had a depth of approximately $1 \mathrm{~m}$. Five of the stream reaches were directly associated with a DRIP groundwater well, and five directly with a non-DRIP well. Two additional DRIPs were identified after installation of GW wells, and are therefore without a well and groundwater samples (Fig. 2, dashed vertical lines). At one stream reach, two DRIPs are located (Fig. 2, marked with 513).

Stream water was collected from the talweg with acid-washed high-density polyethylene bottles. Groundwater wells were sampled using suction cup lysimeters and vacuumed glass bottles, or by using a peristaltic pump to fill acid-washed highdensity polyethylene bottles. The wells were pre-pumped to ensure we did not sample stagnant water. Stream water was collected using grab samples. Bottles for both stream water and groundwater were rinsed three times before filling with minimal headspace. Within 24 hours, all samples were filtered $(0.45 \mu \mathrm{m})$ and kept refrigerated at $4{ }^{\circ} \mathrm{C}$ before analysis. DOC analysis consisted of acidification of the sample, followed by combustion using a Shimadzu TOC- $\mathrm{V}_{\mathrm{CPH}}$. The analysis was repeated at least three times per sample resulting in a DOC concentration in $\mathrm{mg} / \mathrm{l}$ and a percent standard deviation. 


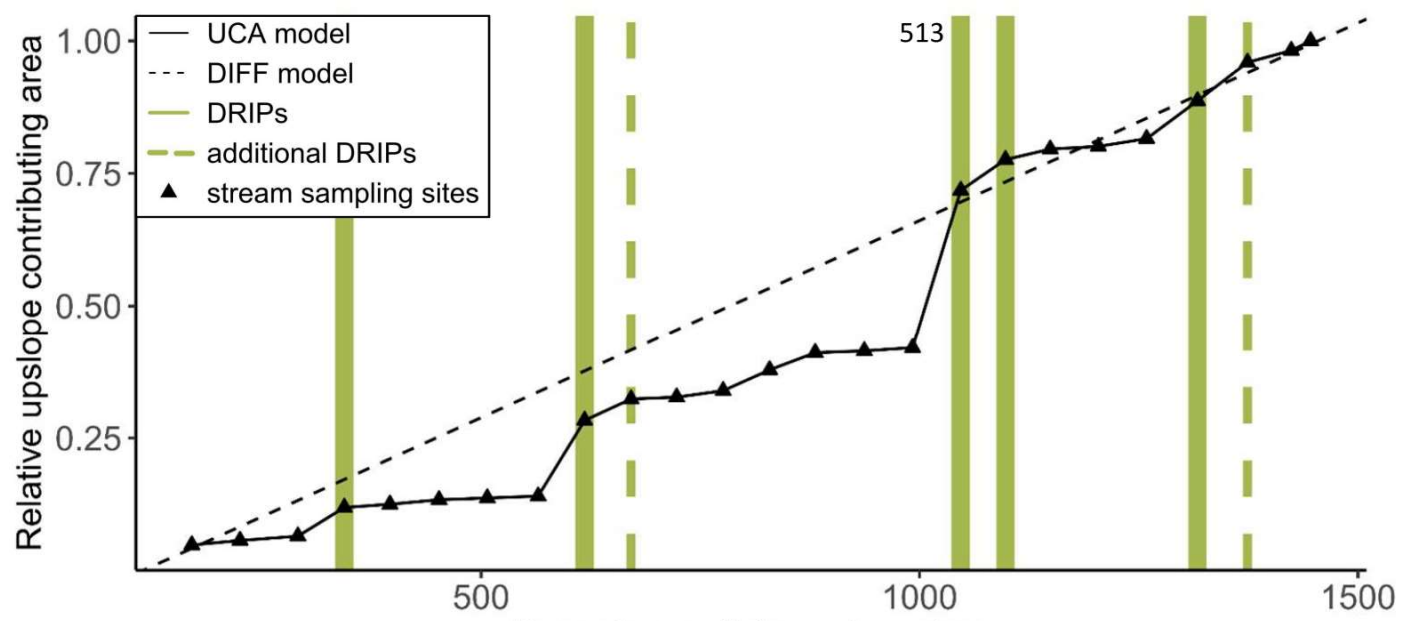

Figure 2 Relative upslope contributing area along the stream reach. The solid line is the relative gain in upslope contributing area between each of the stream sampling sites (triangles), which referred to as UCA model. The dashed line represents the DIFF model, which assumes uniform, diffuse inflow of groundwater along the entire reach. Green vertical bars indicate locations of discrete riparian inflow points equipped by GW wells (DRIPs; solid) and additional DRIP sites without GW wells (dashed). In-stream dissolved organic carbon (DOC) uptake was considered only in those reaches comprising DRIPs (i.e. after the vertical bars).

\subsection{Model framework and data input}

We used a mixing model that considered the stream DOC concentration at location $i$ to be a result of upstream DOC flux and the net lateral riparian groundwater flux that is gained between upstream location $i-1$ and $i$. In addition, we considered that riparian DOC inputs were subjected to in-stream uptake.

$\boldsymbol{D O C}_{\text {stream }, i}=\frac{\left(\boldsymbol{D O C}_{\text {stream }, i-1} * Q_{i-1}\right)+D O C_{g w, i} *\left(Q_{i}-Q_{i-1}\right)-\text { uptake }_{i}}{Q_{i}}$

where $D O C_{\text {stream }, i}$ and $D O C_{\text {stream, } i-1}$ are the stream DOC concentration at location $i$ and $i-1$, respectively; $Q_{i}$ and $Q_{i-1}$ are the streamflows at locations $i$ and $i-1$, respectively; $D O C_{g w, i}$ is the groundwater DOC concentration at location $i$, and uptake $e_{i}$ is the in-stream DOC uptake associated with lateral groundwater labile DOC inputs (see below). We used this equation in combination with different assumptions for the terms that represent streamflow and in-stream uptake.

\subsubsection{Riparian groundwater DOC concentrations}

Out of the 25 stream reaches, there were ten reaches where $\mathrm{DOC}_{\mathrm{gw}}$ was directly obtained from DRIP and non-DRIP wells. From the remaining 15 reaches, 13 were classified as non-DRIP zones and were represented by the chemistry of the nearest non-DRIP wells. When $\mathrm{DOC}_{\mathrm{gw}}$ in non-DRIP wells were not available, their $\mathrm{DOC}_{\mathrm{gw}}$ was weighted based on the mean of all other non-DRIP wells. The remaining 2 stream reaches were classified as DRIPs because these stream reaches had comparable UCA to DRIPs: both reaches exceeded the $75^{\text {th }}$ percentile of the gained upslope contributing area (UCA) relative to catchment area, similar to DRIP reaches. In these two cases, $\mathrm{DOC}_{\mathrm{gw}}$ was considered as the mean of all DRIP wells (Fig. 2, dashed vertical bars). Lastly, the $\mathrm{DOC}_{\mathrm{gw}}$ at the stream location indicated with 513 in Figure 2 had two DRIPs flowing into the stream at the same location. Here $\mathrm{DOC}_{\mathrm{gw}}$ was a weighted average based on the $\mathrm{DOC}_{\mathrm{gw}}$ of both DRIP wells. For the averaging, the UCA of the two DRIP wells relative to the total gain in UCA at that location was used. On 2018-05-11, DOC $\mathrm{gw}_{\mathrm{gw}}$ of both wells was not available, and therefore we considered the mean of the other DRIP wells. 


\subsubsection{Streamflow and lateral groundwater inputs}

Streamflow at each location $\left(Q_{i}\right)$ was considered in two ways. Both approaches assume that all net gain in streamflow between the two hydrological stations C5 and C6 is a result of shallow lateral groundwater input from the RZ. One scenario assumed that the local gains in streamflow were driven by diffuse groundwater inflow (hereafter referred as "DIFF", Fig. 2), where the net gain in streamflow is distributed according to gained stream distance:

$Q_{\text {diff }, i}=\left(Q_{C 6}-Q_{C 5}\right) * \frac{\left(L_{i}-L_{i-1}\right)}{L_{t o t a l}}$

where $Q_{C 5}$ and $Q_{C 6}$ is the streamflow at the gauging stations C5 and C6, respectively (both in $1 / \mathrm{s}$ ). $L_{\text {total }}$ is the total length of the C5-C6 stream segment $(1200 \mathrm{~m}), L_{i}$ is distance between C5 and the sampling location $i$, and $L_{i-1}$ the distance of the upslope stream sampling location.

The other scenario (hereafter referred as "UCA", Fig. 2) was based on Leach et al. (2017), in which lateral groundwater inputs were distributed proportional to the gain in upslope contributing area at each riparian reach:

where $U C A_{i}$ is the upslope contributing area that is gained along the reach (between locations $i$ and $i-1$ ), which was used to distribute the net gained streamflow $\left(Q_{C 6}-Q_{C 5}\right)$ proportional to the total gain in catchment area between the lake and the downstream outlet $\left(A_{C 6}-A_{C 5}\right)$. This approach emphasized the hydrological contributions of DRIPs, because of their large contributing areas relative to the rest of the RZ.

\subsubsection{In-stream DOC processing}

We considered two different scenarios regarding in-stream DOC processing. One scenario considered that the stream was acting as a passive pipe for DOC (i.e. no in-stream DOC uptake), while the other scenario considered that stream biota rapidly take up the DOC originating from lateral groundwater inputs. We did not consider the scenario that DOC coming from upstream locations were taken up along the stream, as previous studies in Krycklan have suggested that this rarely occurs (Tiwari et al., 2014).

At each location (i), in-stream DOC uptake of lateral groundwater DOC inputs (uptake ${ }_{i}$, in $\mathrm{mg} \mathrm{C} / \mathrm{s}$ ) was estimated as follows:

where $D O C_{g w, i}$ is the DOC concentration of riparian groundwater (in $\mathrm{mg} / \mathrm{l}$ ), $V f$ the DOC uptake velocity (in $\mathrm{mm} / \mathrm{min}$ ) associated with riparian carbon, and width $_{i}$ and $l e n g t h_{i}$ are the mean channel width and the reaction path length of each reach (both in $\mathrm{m}$ ). Based on previous work at this particular study segment, we assumed that in-stream DOC uptake mostly occurred immediately downstream of DRIPs (Lupon et al., 2019). We accounted for this by setting the length of all reaches to zero, except for those where a DRIP was located (Fig. 2). At these reaches, lengt $h_{i}$ was the distance between DRIPs and the location $i$, instead of the total length between $i-1$ and $i$. This prevented overestimations of reaction times and path lengths 
over which in-stream uptake took place. For in-stream DOC uptake from riparian groundwater, we used a $V f=0.6 \pm 0.06$ $\mathrm{mm} / \mathrm{min}$. This value is the median ambient DOC $V f$ obtained from a literature review and has been shown to realistically simulate in-stream DOC uptake at whole river networks (Mineau et al. 2016). Because $V f$ depends on temperature, streamflow, DOC composition, and microbial assemblages, we tested values for $V f$ ranging between 0.25 and $1.11 \mathrm{~mm} / \mathrm{min}$ yielded. These values yielded similar model results for the simulations that considered in-stream DOC uptake (Fig. S2).

\subsection{Model scenarios, uncertainties and performance criteria}

In total, our model approach resulted in four scenarios per sampling campaign (Table 1). For each sampling date, the model scenarios were informed with the same $\mathrm{DOC}_{\mathrm{gw}}$ concentrations, but assumed different representations of catchment hydrology and in-stream DOC processing. "DIFF_NOBIO" assumes diffuse groundwater inputs and passive transport of DOC in the stream. "DIFF_BIO" also assumes diffuse groundwater inputs, but accounts for in-stream DOC uptake downstream from DRIPs. The "UCA_NOBIO" model assumes that groundwater inputs are distributed proportional to their UCA and no instream DOC uptake, which means that DRIPs contribute a relatively large component of the net gained stream water compared to non-DRIP stream sections. The "UCA_BIO" model assumes groundwater inputs proportional to UCA as well, and accounts for in-stream DOC uptake downstream from DRIPs.

Table 1 Overview of model assumptions. First column indicates model name. Second column indicates whether the streamflow is assumed as uniform diffuse rate along the reach, or distributed based on upslope contributing area. The third column indicates whether in-stream uptake of DOC by biota is included.

\section{MODEL SCENARIO}

DIFF_NOBIO
DIFF_BIO
UCA_NOBIO
UCA_BIO

\section{HYDROLOGY}

$\begin{array}{ll}\text { Diffuse } & \text { No uptake } \\ \text { Diffuse } & \text { Uptake } \\ \text { Upslope contributing area } & \text { No uptake } \\ \text { Upslope contributing area } & \text { Uptake }\end{array}$

To account for uncertainties in our streamflow observations, water sample analysis and model assumptions, we used a stochastic approach to evaluate our model simulations. This means that we compared the range of uncertainty in our simulations to the range of uncertainty in the observations. For each scenario we executed a 100 model runs, with each run using a randomized sample for every observation and every computation. We presented the simulated $D O C_{\text {stream }, i}$ using an uncertainty band that represented $66 \%$ of the randomized model runs (mean $+/$ - one standard deviation). The randomizations for each sample were based on normal distributions considering $10 \%$ uncertainty of streamflow observations and DOC uptake velocity, and the percentage standard deviation from the laboratory analysis (for most samples this was $<2 \%$ ). For each run, the model generates a single ("deterministic") value for $D O C_{\text {stream, } i}$. This means that for the next downstream location the gained uncertainty (from the streamflow, DOC uptake velocity and laboratory analysis) is incorporated as a single value of $D O C_{\text {stream, } i-1}$. As such, DRIPs can have large influence on the uncertainty band and sampling days with relative large gains in streamflow from groundwater inputs can have increasing uncertainty bands further downstream. In the case that upstream from location $i$ the uncertainty band in $D O C_{\text {stream }}$ was large, but the uncertainty of the lateral input at location $i$ was small, the uncertainty band can become narrower.

We evaluated the simulations using a number of goodness of fit metrics, computed using the "hydroGOF" R-package (Zambrano-Bigiarini, 2020). We computed the root mean squared error (RMSE), percent bias (PBIAS), Nash-Sutcliffe efficiency (NSE), and coefficient of determination $\left(\mathrm{R}^{2}\right)$ for each sampling. RMSE aggregates the magnitude of errors in $\mathrm{mg} / \mathrm{l}$. We considered a $2 \mathrm{mg} / 1$ magnitude of error acceptable. PBIAS shows systematic errors in the simulations as a percent deviating 

$5 \%$ bias acceptable. NSE ranges from $-\infty$ to 1 , and shows how the variance of the simulation corresponds to the variance in observations. $\mathrm{R}^{2}$ compares variances as well, but the simulated and observed variance is considered a cloud of points, which does not account for the ability of to simulate patterns in the observations. For both NSE and $\mathrm{R}^{2}$, we considered that values > 0.5 were indicating that the model was capturing the general direction and variance of stream DOC concentrations. For $\mathrm{R}^{2}$, these assumption was only true if the relation between observed and simulated stream DOC concentrations was positive.

\section{Results}

During the study period, the net gain in streamflow along the segment ranged between $8 \%$ and $90 \%$, with an average of $37 \%$ (Fig. S1). Stream DOC concentration ranged between 15 to $32 \mathrm{mg} / 1$ and generally decreased along the C5-C6 stream segment (11 out of 15 sampling campaigns) (Fig. 3). The variability in stream DOC concentration along the segment and across different flow conditions was reasonably well captured by all models because, although the models rarely captured the entire longitudinal pattern, the order of magnitude of the simulations was within the range of the observations, and the general direction of the simulated values corresponded with the observations. For the majority of the simulations, RMSE were in the order of $2 \mathrm{mg} / 1$ and PBIAS was within a range of $-5 \%$ to $5 \%$ (Table 2). Further, for 10 out of 15 sampling campaigns, at least one model had an $\mathrm{R}^{2}$ greater than 0.5 (Table 2). However, only in four sampling campaigns, the NSE of at least one model was greater than 0.5 (Table 2, Fig. 3F, K-M).

\subsection{Snowmelt 2017}

The sampling campaigns of spring 2017 captured an early snowmelt peak, and the receding limb of a rain-on-snow event (Fig 3A-E). At the onset of the snowmelt peak, stream DOC concentration ranged between 25 and $30 \mathrm{mg} / 1$ and showed a marked longitudinal pattern (Fig. 3A-B). In the first sampling campaign, the two scenarios assuming diffusive groundwater inputs captured the decreasing trend of stream DOC concentration in the first $700 \mathrm{~m}$, but underestimated the concentrations at the downstream section of the stream segment (Fig. 3A). In the second sampling campaign, none of the models correctly captured the longitudinal patterns of stream DOC concentrations ( NSE $<0)$, as all them simulated uniform concentrations around 27 $\mathrm{mg} / \mathrm{l}$ (Fig. 3B). Around the time of the rain-on-snow event, stream DOC concentrations were more uniform along the section than during the two previous sampling days, ranging between 15 and $20 \mathrm{mg} / 1$ (Fig. 3C-D). The headwater lake contributed the majority of the stream water during these sampling campaigns (Fig S1). During sampling campaign C, between the snowmelt and rain-on-snow event, the UCA_NOBIO scenario yielded the lowest RMSE and PBIAS, and highest R² (Fig. 3C). For all scenarios, NSE $<0$. The second rain-on-snow sampling campaign had similar flow conditions as $\mathrm{C}$, but none of the scenarios resulted in an accurate simulation (Fig. 3D, Table 2). During the post-snowmelt low flow on 2017-06-02 (Fig. 3E), step changes in stream DOC concentrations that coincided with DRIPs were well captured by the two scenarios that consider in-stream uptake (NSE=0.81 and NSE=0.5 for the "DIFF_BIO" and "UCA_BIO" models, respectively). For those scenarios, the RMSE and PBIAS were also acceptable. By contrast, the scenarios without in-stream uptake ("DIFF_NOBIO" and "UCA_NOBIO") did not meet our criteria, except for $\mathrm{R}^{2}$.

\subsection{Experimental drought 2017}

The sampling campaigns in the summer of 2017 (Fig. 3F-J) consisted of a rain event, an experimental drought, a controlled lake water flood pulse and post-flood base flow conditions. The absolute gain in streamflow was small during these sampling campaigns (0-5 1/s), but the relative gain varied between $9 \%$ and $90 \%$ (Fig S1). During the rain event and the drought, stream DOC concentration increased along the segment (between 17 and $28 \mathrm{mg} / \mathrm{l}$ ) and distinct step changes in DOC concentrations occurred at the locations where DRIPs flow into the stream (Fig. 3F-H). For the rain event, none of the models accurately 
simulated the observed patterns (Fig. 3F). For the first drought sampling campaign, the model "DIFF_NOBIO" most accurately

simulated the longitudinal variability in stream DOC concentration ( $N S E=0.48$, Table 2 ), while the two models that accounted for in-stream DOC uptake ("DIFF_BIO" and "UCA_BIO") underestimated stream DOC concentrations and were partially out of bounds (Fig. 3G). "UCA_NOBIO" overestimated stream DOC concentrations along the entire stream section (Table 2). The second drought sampling campaign showed similar model results, but the pattern produced by scenario "DIFF_NOBIO" was less successful (Fig. $3 \mathrm{H}$ ). The following flood pulse and post-flood base flow conditions resulted in uniform stream DOC

295 concentrations along the stream segment. Subsequently, all models had low RMSE and PBIAS, but NSE indicated that patterns were not well reproduced (Fig. 3I-J, Table 2).

\subsection{Snowmelt 2018 and 2019}

In the spring of 2018 and 2019, mostly snowmelt peak flow conditions were captured (Fig S1), which were characterized by flows exceeding 100 l/s and diurnal snowmelt patterns. In all sampling campaigns, stream DOC concentrations generally decreased along the stream segment, yet there were step changes indicating either dilution or enrichment of DOC at the DRIP locations (Fig. 3K-O). Our modelling results show that, for the 2018 spring flood, pattern simulations met all our criteria for at least one scenario (Fig 3K-M, Table 2). The scenario that better fit the data were the "UCA_NOBIO", the "DIFF_BIO" and the "UCA_BIO", for the first, second and third sampling campaigns, respectively (Fig 3K-M, Table 2). During the 2019 spring peak flow, both "UCA" scenarios overestimated stream DOC concentrations at two DRIPs, while the "DIFF" scenarios more closely represented the observations (Fig. S1 and Fig. 3N). Further, none of the models performed well (NSE and $\mathrm{R}^{2}<0.5$; Table 2). In the receding limb of the snowmelt peak flow, none of the models were able to capture the increments in stream DOC concentration between DRIPs (Fig. 3O). 
https://doi.org/10.5194/hess-2021-358

Preprint. Discussion started: 28 July 2021

(c) Author(s) 2021. CC BY 4.0 License.

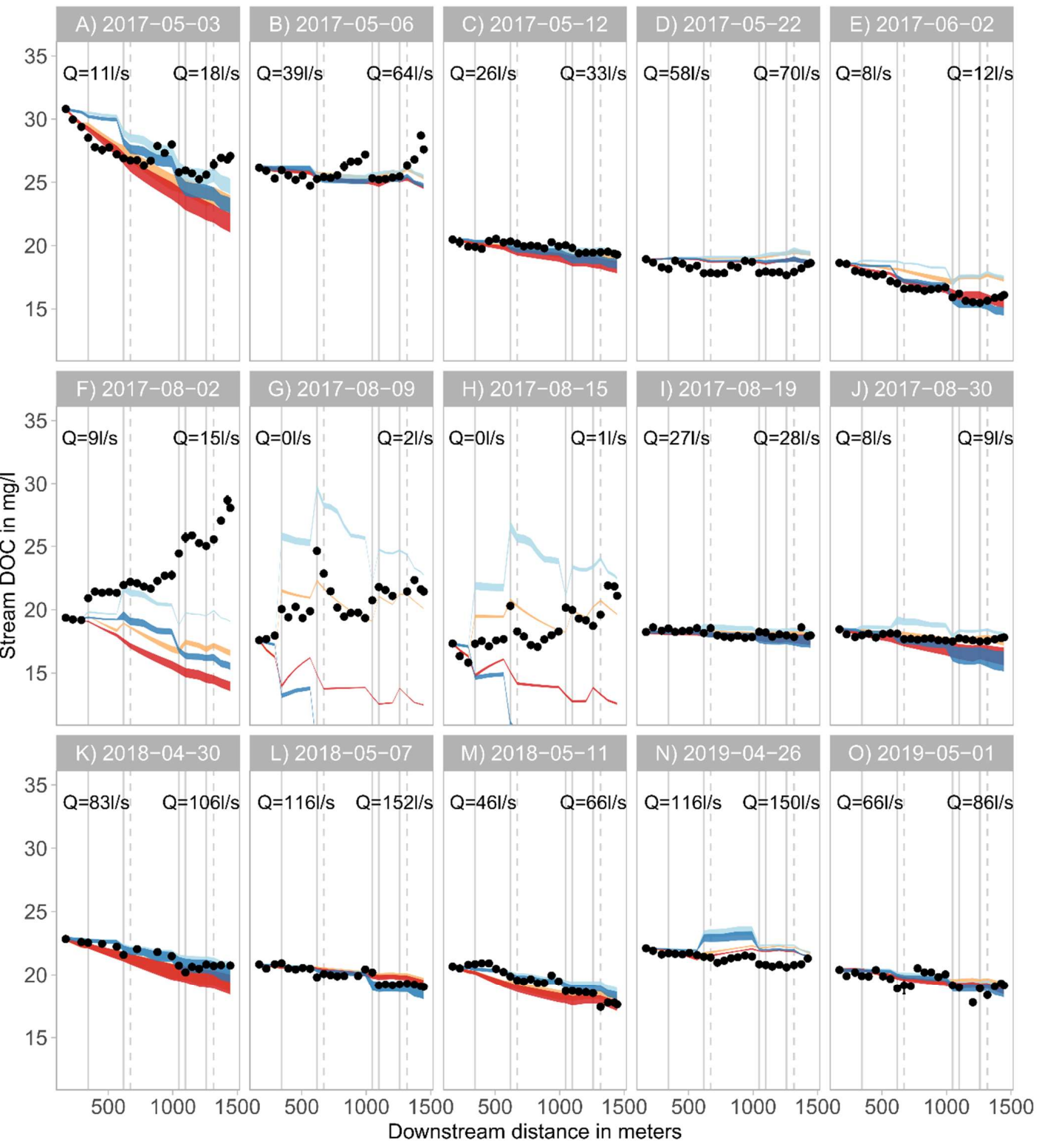

diff_nobio uca_nobio diff_bio uca_bio

310 Figure 3 Longitudinal patterns of stream dissolved organic carbon (DOC) concentrations along the C5-C6 stream segment. Each panel, indicated by label and date, shows one sampling campaign. The black dots are the observed stream DOC concentrations. The coloured bands show the simulations of the four models. The vertical grey lines show the locations of DRIPs with wells (solid) and DRIPs without wells (dashed). The streamflow (Q) at gauging stations $\mathrm{C} 5$ and $\mathrm{C6}$ are shown for each sampling campaign. 
https://doi.org/10.5194/hess-2021-358

Preprint. Discussion started: 28 July 2021

(c) Author(s) 2021. CC BY 4.0 License.

315 Table 2 Model performance by sampling campaign. Each box represents a sampling campaign, indicated with A-O. The letters correspond to the panels in Figure 3. For each model, the goodness of fit metrics RMSE, PBIAS, NSE and $\mathbf{R}^{2}$ are presented. The bold numbers indicate that the value was considered acceptable based on our criteria in section 2.4.

DATE MODEL

RMSE PBIA NSE $\mathbf{R}^{2}$ [MG/L S

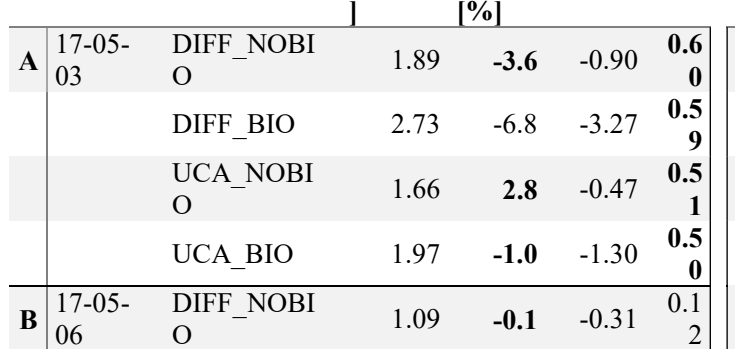

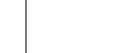

DIFF BIO

UCA_NOBI

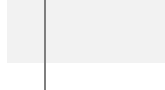

\begin{tabular}{l|l} 
C & $\begin{array}{l}17-05- \\
12\end{array}$
\end{tabular}

UCA_BIO

1.2

$1.04-0.1$

DIFF_NOBI

DIFF_BIO

UCA_NOBI

$\mathrm{O}$

1.3

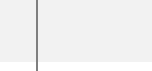

D

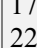

E

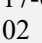

17-08-

02

17-08- DIFF_NOBI

09

H

$\mathrm{O}$

DIFF BIO

UCA_NOBI

$\mathrm{O}$

$\begin{array}{llllr}\text { UCA_BIO } & 11.34 & -50 & -44.99 & 0.5 \\ 7\end{array}$

$\begin{array}{llll}\mathbf{0 . 6 1} & \mathbf{- 2 . 4} & -0.99 & \mathbf{0 . 5}\end{array}$

$\mathbf{0 . 8 8} \quad \mathbf{- 3 . 4}-4.68 \quad 0.4$

$\mathbf{0 . 5 6} \quad \mathbf{- 1 . 7}-0.81 \quad \mathbf{0 . 5}$

$\mathbf{0 . 9 4} \quad \mathbf{- 3 . 6}-4.28 \quad \mathbf{0 . 5}$

$\begin{array}{rrrr}1.09 & 5.3 & -6.6 & 0.1 \\ & & 0\end{array}$

L 18-05-

$\begin{array}{llll}\mathbf{0 . 7 1} & \mathbf{3 . 3} & -2.42 & 0.0 \\ & & \end{array}$

$\begin{array}{llll}.07 & 5.2 & -6.05 & 0.1\end{array}$

$\begin{array}{lllr}\mathbf{0} 68 & 3.2 & -2.58 & 0.0 \\ & & 5\end{array}$

DIFF_NOBI

DIFF_BIO

1.2

UCA_NOBI

$\mathrm{O}$

UCA_BIO

0.4

$\begin{array}{llll}1.62 & 8.9 & -1.93 & \mathbf{0 . 6}\end{array}$

$\begin{array}{lllr}0.65 & 0.2 & 0.50 & 0.8\end{array}$

DFF_NOBI

DIFF_BIO

$\begin{array}{llll}6.28 & -22.6 & -4.77 & 0.7\end{array}$

UCA NOBI

$\begin{array}{llll}7.96 & -28.7 & -8.16 & 0.8\end{array}$

$\begin{array}{llll}4.24 & -13.5 & -1.69 & 0.0\end{array}$

$\begin{array}{llll}6.52 & -22.2 & -5.29 & 0 .\end{array}$

$\begin{array}{llll}1.16 & \mathbf{- 1 . 3} & 0.48 & \mathbf{0 . 5}\end{array}$

$\begin{array}{lllll}6.91 & -30.9 & -16.57 & 0.4\end{array}$

$\begin{array}{llll}5.06 & 20.8 & -8.87 & 0.3\end{array}$

DIFF_NOBI

1.57

4.4
8-05-

DATE MODEL

RMSE PBIA NSE R

[MG/L S

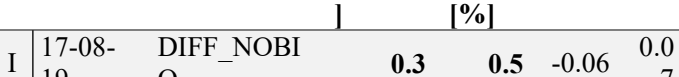

$19 \quad \mathrm{O}$

DIFF BIO

UCA_NOBI

$\mathrm{O}$

UCA_BIO

J $17-08-$

DIFF_NOBI

DIFF_BIO

UCA_NOBI

$\mathrm{O}$

UCA_BIO

K 18-04-

DIFF_NOBI

DIFF_BIO

UCA_NOBI

$\mathrm{O}$

UCA_BIO

DIFF_NOBI

$\mathrm{O}$

DIFF_BIO

UCA_NOBI

$\mathrm{O}$

UCA_BIO

0.25

$\begin{array}{rrr}\mathbf{0 . 3} & 0.11 & 0.2 \\ 6\end{array}$

$\begin{array}{rrrr}0.4 & 1.2 & -1.1 & 0.1 \\ \end{array}$

$\begin{array}{lllr}0.29 & 0.6 & -0.03 & 0.2 \\ 4\end{array}$

\begin{tabular}{lllr}
0.3 & 0.9 & 0.03 & 0.5 \\
\hline
\end{tabular}

$\begin{array}{llrr}1.0 & -4.4 & 12.37 & 0.4\end{array}$

$\begin{array}{llll}0.9 & 4.6 & -8.42 & 0.0\end{array}$

\begin{tabular}{lllr}
$\mathbf{0 . 3 5}$ & $\mathbf{1 . 1}$ & -0.91 & 0.2 \\
\hline
\end{tabular}

$\begin{array}{rrrr}1.26 & -5.3 & -1.31 & \mathbf{0 . 8} \\ & & & \mathbf{4}\end{array}$

$\begin{array}{rrrr}1.18 & -\mathbf{4 . 8} & -1.05 & \mathbf{0 . 8}\end{array}$

$\begin{array}{lllr}0.36 & 0.1 & 0.83 & 0.9 \\ 0\end{array}$

\begin{tabular}{lllr}
0.63 & -2.1 & 0.44 & 0.8 \\
\hline
\end{tabular}

$\begin{array}{lllr}0.38 & 0.9 & 0.62 & 0.7\end{array}$

$\begin{array}{rrrr}0.34 & 0.9 & 0.69 & 0.7\end{array}$

$\mathbf{0 . 8 2} \quad \mathbf{- 2 . 6}-0.68 \quad \mathbf{0 . 8}$

\begin{tabular}{rrrr} 
& & 31 & $\mathbf{3}$ \\
\hline $\mathbf{2}$ & $\mathbf{- 2 . 4}$ & -0.77 & $\mathbf{0 . 8}$
\end{tabular}

\begin{tabular}{rrrrr} 
& 0.81 & -2.4 & -0.77 & $\mathbf{0}$ \\
\hline & & & & 2
\end{tabular}

\begin{tabular}{llllr}
$\mathrm{O}$ & 0.68 & -2.2 & 0.63 & 0.7 \\
\hline
\end{tabular}

$\begin{array}{llllr}\text { DIFF_BIO } & \mathbf{0 . 9 2} & \mathbf{- 4} & 0.27 & \mathbf{0 . 8} \\ \mathbf{0}\end{array}$

$\begin{array}{lllll}\text { UCA_NOBI } & 0.71 & 2.1 & 0.59 & 0.9\end{array}$

$\mathrm{O} \quad \mathbf{0 . 7 1}$

\begin{tabular}{lllrr} 
UCA_BIO & 0.4 & 0.4 & 0.85 & 0.9 \\
\hline
\end{tabular}

$\begin{array}{llllr}\text { DIFF_NOBI } & \mathbf{0 . 8 7} & \mathbf{3} & -3.36 & 0.2 \\ \mathrm{O} & & & & \end{array}$

$\begin{array}{lllrr}\text { DIFF_BIO } & \mathbf{0 . 6 8} & \mathbf{2 . 3} & -1.46 & 0.0 \\ 1\end{array}$

$\begin{array}{lllll}\text { UCA NOBI } & 1.79 & 6.7 & - & 0.0\end{array}$

$\mathrm{O}$

$\begin{array}{llllll}\text { UCA_BIO } & 1.52 & 5.8 & - & 0\end{array}$

$\begin{array}{lllll}\text { DIFF_NOBI } & \mathbf{0 . 6 5} & 0.4 & 0.2 & 0.2\end{array}$

\begin{tabular}{llllr}
$\mathrm{O}$ & $\mathbf{0 . 6 5}$ & 0.4 & 0.2 & 0.2 \\
\hline
\end{tabular}

$\begin{array}{llllr}\text { DIFF_BIO } & \mathbf{0 . 6 7} & -0.2 & 0.18 & 0.2 \\ 7\end{array}$

\begin{tabular}{lllll} 
UCA_NOBI & $\mathbf{0 . 6 5}$ & -0.7 & 0.19 & 0.4 \\
\hline
\end{tabular}

$\mathrm{O}$

UCA_BIO

$\mathbf{0 . 7 1} \quad-0.8 \quad-0.13 \quad 0.3$ 


$\begin{array}{llllr}\text { DIFF_BIO } & 5.1 & -23.1 & -9.01 & 0.5 \\ \text { UCA_NOBI } & & & & 0.1 \\ \text { O } & 4.78 & 22.4 & -7.99 & 2 \\ \text { UCA_BIO } & 8.66 & -39.5 & -28.02 & 0.6 \\ & & & & 3\end{array} \mid$

\section{Discussion}

Our observations showed that longitudinal stream DOC concentrations between the two gauging stations varied spatially during different flow conditions. While during some sampling campaigns stream DOC concentration was uniform along the stream segment (around $20 \mathrm{mg} / \mathrm{l}$ ), at other occasions it varied between 15 and $30 \mathrm{mg} / 1$. Especially at DRIPs, we observed step changes in stream DOC concentrations, indicating that DRIPs can both decrease and increase stream DOC concentrations. We considered that these changes can be attributed to dilution and enrichment of DOC, as well as to in-stream removal of DOC. To understand what controlled patterns of stream DOC concentrations at the various flow conditions, we simulated stream DOC concentrations based on terrestrial DOC fluxes and local in-stream DOC uptake. We compared four different model scenarios with the observed stream DOC profiles. Our results showed that including DRIPs in a stream-based mixing model for DOC helps to explain longitudinal patterns through both terrestrial source-transport mechanisms as well as in-stream uptake of DOC.

Our modelling exercise demonstrated that accounting for spatial variability in lateral groundwater inputs can improve simulations of stream DOC dynamics that occur along the stream segment. Most step changes in DOC coincided with DRIP locations, which suggests that supply of DOC was an important influence on stream DOC concentrations. The different patterns simulated by model scenarions DIFF_NOBIO and UCA_NOBIO shows that acknowledging spatial variability in hydrology can improve stream DOC simulations, or at least indicate where step changes occur. For example during the snowmelt event of 2018 the model scenario UCA_NOBIO was able to represent step changes in stream DOC concentrations that coincide with the location of DRIPs (Fig. 3K and Table 2). This corroborates that spatial variability in groundwater hydrology related to landscape organization has a major influence stream DOC patterns (Covino et al., 2021; Dupas et al., 2021; Rocher-Ros et al., 2019). As such, model frameworks that integrate the spatial variability in hydrology from hillslopes to stream reaches and catchments can help represent variability in hydrological connectivity between gauging stations (Jencso et al., 2009; Seibert

340 et al., 2009). However, the other sampling campaigns show that for most of the flow conditions, the hydrology is only one of the components that explains stream DOC patterns. As such our findings suggests it is equally important to represent of spatial variability in $\mathrm{C}$ sources in relation to landscape organization, as well as the associated biogeochemical dynamics (Grabs et al., 2012; Hale and Godsey, 2019; Wollheim et al., 2018).

345 We showed that accounting for in-stream DOC uptake improved predictions of longitudinal stream DOC concentrations during medium flow conditions (from 10 to 50 1/s). Especially, the example in June 2017 (Fig 3E) shows how step changes are accurately reproduced by the "UCA_BIO" scenario. However, during extremely high and low flows, in-stream DOC uptake did not contribute to longitudinal stream DOC concentrations. These results concur with previous studies recently performed in headwaters (Lupon et al., 2019; Seybold and McGlynn, 2018), and suggest that aquatic biological activity becomes enhanced

350 at the transition between low and high flows due to increases in labile DOC supply from terrestrial systems. However, our results also support the idea that, beyond a certain flow threshold ( $>1001 / \mathrm{s})$, the benefits of increased substrate supply become overwhelmed by low water residence times and physical disturbance (Raymond et al. 2016). Interestingly, we observed that the influence of in-stream processes on water chemistry was minimal during low flows. A possible explanation for the observed behaviour is that, during the experimental drought, stream reaches were longitudinally disconnected from each other and 

results indicate that the pipe vs reactor behaviour of boreal headwater streams is closely tied to changes in lateral inputs of DOC from RZ.

Our model framework represented the source of lateral DOC inputs based on groundwater samples from a riparian well network that compared DRIP and non-DRIP groundwater chemistry (Ploum et al., 2020). This allowed to distinguish between the spatial variability in riparian groundwater chemistry associated with different soil wetness regimes (Vidon, 2017). For example during snowmelt conditions, when occasionally DRIP water can be routed over ice (Ploum et al., 2018), local decreases in DOC concentrations in stream DOC concentrations were captured by the model. Also during the experimental drought, the representation of spatial variability in groundwater was more important that hydrology or in-stream uptake: during the experimental droughts, the scenario that approximated the stream DOC patterns the most was the "DIFF_NOBIO". This result suggests that, under conditions as these, stream DOC patterns might not be directly related to the quantity of groundwater inputs, but rather to the thermal and chemical conditions that groundwater discharge creates at the local level (Briggs and Hare, 2018). However, we also see limitations of our groundwater sampling approach. For example, our groundwater sampling campaigns were not able to represent temporal DOC dynamics associated with variability in groundwater travel times (Heidbüchel et al., 2020), event scale variability in riparian DOC mobilization (Werner et al., 2019), or the activation of DOC from different soil layers (Ledesma et al., 2018).

Apart from the limitations of our groundwater sampling campaigns, we identified other limitations in the hydrological components and the in-stream uptake components of the model as well. The sampling campaign of a rain event on 2017-0802 (Fig. 3F) is a clear example of mismatch between our simulations and the observations: while stream DOC concentrations increased along the reach, our model scenarios simulated a decreasing pattern. The observed step changes in stream DOC concentrations at the DRIPs is in agreement with the consistently high DOC loads that are characteristic for DRIP groundwater (Ploum et al., 2020). Also, during the rising limb of the snowmelt event (Fig. 3B), discrepancies were found between our simulations and the observed patterns: our model scenarios produced a uniform DOC pattern, while the observations showed increasing DOC concentrations along the reach which abruptly decreased at DRIPs. This observed pattern can be explained by activation of organic top soils at non-DRIP reaches by rising groundwater levels (Ledesma et al., 2018) and by overland or over-ice flow at DRIPs (Ploum et al., 2018). These examples and the observed patterns that can be explained by our previous work, suggests that the model framework and the data input have some limitations representing the dynamics of streamflow generation along the stream segment. It is likely that there is discrepancy between our spatial distribution of gained streamflow based on UCA and the effective runoff to streams during different flow conditions (Ambroise, 2004; Klaus and Jackson, 2018). Especially, during the spring snowmelt, our model scenarios do not capture the complexity of flow paths and the timing of lateral inputs that are associated with snowmelt hydrology (Laudon et al., 2004; Lyon et al., 2010). Besides the source-transport mechanisms on hillslope scale, other catchment characteristics affected the performance of the model as well. For example, during some high flow conditions (Fig. 3K-M, Fig S1) the lateral groundwater inputs were relatively small compared to the streamflow contributions of the upstream lake (Leach and Laudon, 2019). In these cases, the observed DOC pattern was fairly uniform, which made it less challenging for the different scenarios to meet our performance criteria. Also, for event-scale dynamics during rain or snowmelt events, the lake was potentially an important influence on stream conditions along this segment: while the lateral groundwater inputs respond quickly to rain or snowmelt, the lake response can be delayed (Leach and Laudon, 2019).

For the in-stream uptake component of our model, we did not take into account processes that produce (i.e. resuspension) or remove (i.e., photodegradation, adsorption) DOC from the water column. Further, in-stream DOC uptake was assumed to 
occur only downstream of DRIPs and at a uniform rate across flow conditions. Previous studies have shown that uptake rates can vary over time as a function of temperature, DOC composition, and microbial assemblages (Berggren et al., 2009; Mineau et al., 2016). While the use of other values for $V f$ resulted in similar model output (Fig. S2), we cannot discard the idea that $V f$ varied among DRIPs and/or over time due to changes in groundwater DOC composition and temperature. Regardless, our model framework demonstrated that UCA can be useful to identify "reactive" reaches by considering DRIPs as major locations of biological activity. Similarly, others have demonstrated that spatial patterns in DOC concentrations along headwaters are associated with biological activity and stream water permanence driven by terrestrial flow path organization (Lupon et al., 2019, Hale and Godsey, 2019).

For future studies, we have identified two directions that can be useful to improve our simulations of stream DOC dynamics along boreal headwaters. For the representation of the spatial heterogeneity in riparian hydrochemistry, the hydrological representation of lateral groundwater inputs through the distinction of DRIP and non-DRIP riparian zones can be further developed. For this matter, integrative hydrochemical frameworks that represent fluxes from various soil layers would be useful to include, especially at non-DRIPs because here groundwater levels are more dynamic compared to DRIPs (Seibert et al., 2009). Furthermore, it can be of interest to downscale the number riparian groundwater chemistry samples to understand what minimum set of groundwater samples is required to represent the spatial heterogeneity in sources of lateral DOC inputs from RZs to streams. A preliminary analysis indicated that the most optimal strategy to reduce model uncertainty was to

415 monitor DRIPs individually, while averaging DOC concentrations at non-DRIPs (Ploum, 2021). However, given that nonDRIP groundwater chemistry changes with groundwater table fluctuations (Ledesma et al., 2015; Ploum et al., 2020), it is likely that optimizing groundwater sampling campaigns requires careful consideration of the antecedent groundwater conditions.

\section{Conclusions}

The objective of this study was to understand the influence of discrete riparian inflow points (DRIPs) on longitudinal patterns of stream DOC concentrations along a headwater reach. More specifically, our aim was to integrate source-transport mechanisms and in-stream uptake in a model framework, by considering DRIPs as the primary driver of both hydrological and biogeochemical processes that influence patterns of stream DOC concentrations. The purpose of this modelling exercise was to disentangle the role of terrestrial DOC inputs and in-stream uptake during different flow conditions. We found that sourcetransport mechanisms as well as the in-stream uptake associated with DRIPs had occasionally a large influence on longitudinal DOC patterns. The different model scenarios showed that depending on flow conditions, the dominant influence of lateral groundwater inputs and in-stream uptake on stream DOC patterns shifted. As such, the identification and characterization of groundwater chemistry of DRIPs can be used to represent major lateral groundwater inputs to stream channels, and to highlight reactive reaches within stream networks. This study contributes to the greater goal of integrating hydrological and biogeochemical models ( $\mathrm{Li}$ et al., 2020), explicit consideration of groundwater discharges in quantitative frameworks (Briggs and Hare, 2018), and the spatial assessment of removal mechanisms of DOC in stream networks (Mineau et al., 2016).

\section{Data availability}

The presented data in this study can be requested through the first author. Krycklan data is openly available through the 


\section{Author contributions}

SP was responsible for study concept, data collection and analysis, model framework, figure compilation, result interpretation, and writing. AL contributed to study concept, data collection, model framework, result interpretation and writing. JL and HL contributed to model framework, result interpretation and writing. LK designed GW well infrastructure and contributed to result interpretation and writing process.

\section{Competing interests}

The authors declare that the research was conducted without commercial or financial support that could be construed as potential conflict of interest.

\section{Acknowledgements}

This study was funded by Oscar and Lili Lamm Foundation and Svenska Forskningsrådet Formas. The Krycklan catchment is also supported by SITES (VR), SKB, KAW and the Kempe Foundation. AL was supported by the program Beatriu de Pinós, funded by the Government of Catalonia and the Horizon 2020 research and innovation program (BP-2018-00082). We acknowledge Andrés Peralta-Tapia for well installations, and the staff at Svartberget research station and Laura Coulson for assisting with sample collection. We thank Kelly Hondula for support with RStudio troubleshooting during analysis and figure compilation.

\section{References}

Alexander, R. B., Boyer, E. W., Smith, R. A., Schwarz, G. E. and Moore, R. B.: The role of headwater streams in downstream water quality 1, JAWRA Journal of the American Water Resources Association, 43(1), 41-59, 2007.

Ambroise, B.: Variable "active" versus "contributing" areas or periods: a necessary distinction, Hydrological Processes, 18(6), 1149-1155, doi:10.1002/hyp.5536, 2004

Antonelli, M., Glaser, B., Teuling, A. J., Klaus, J. and Pfister, L.: Saturated areas through the lens: 1. Spatio-temporal variability of surface saturation documented through thermal infrared imagery, Hydrological Processes, 34(6), 1310-1332, doi:10.1002/hyp.13698, 2020.

Barclay, J. R., Starn, J. J., Briggs, M. A. and Helton, A. M.: Improved Prediction of Management-Relevant Groundwater Discharge Characteristics Throughout River Networks, Water Resources Research, 56(10), doi:10.1029/2020wr028027, 2020.

Berggren, M., Laudon, H., Haei, M., Ström, L. and Jansson, M.: Efficient aquatic bacterial metabolism of dissolved lowmolecular-weight compounds from terrestrial sources, The ISME Journal, 4(3), 408-416, doi:10.1038/ismej.2009.120, 2009.

Bernal, S., Lupon, A., Catalán, N., Castelar, S. and Martı, E.: Decoupling of dissolved organic matter patterns between stream and riparian groundwater in a headwater forested catchment, Hydrol. Earth Syst. Sci, 22, 1897-1910, 2018.

Briggs, M. A. and Hare, D. K.: Explicit consideration of preferential groundwater discharges as surface water ecosystem control points, Hydrological Processes, 32(15), 2435-2440, 2018.

Briggs, M. A., Dawson, C. B., Holmquist-Johnson, C., Williams, K. H. and Lane Jr, J. W.: Efficient hydrogeological characterization of remote stream corridors using drones, Hydrological Processes, 33(2), 316-319, 2019.

Casas-Ruiz, J. P., Catalán, N., Gómez-Gener, L., Schiller, D. von, Obrador, B., Kothawala, D. N., López, P., Sabater, S. and 470 Marcé, R.: A tale of pipes and reactors: Controls on the in-stream dynamics of dissolved organic matter in rivers, Limnology and Oceanography, 62(S1), S85-S94, 2017.

Cole, J., Prairie, Y., Caraco, N., McDowell, W., Tranvik, L., Striegl, R., Duarte, C., Kortelainen, P., Downing, J., Middelburg, J. and others: Plumbing the global carbon cycle: integrating inland waters into the terrestrial carbon budget, Ecosystems, 10(1), $172-185,2007$. 
475 Covino, T., Riveros-Iregui, D. A. and Schneider, C. L.: Geomorphology Imparts Spatial Organization on Hydrological and Biogeochemical Fluxes, in Reference Module in Earth Systems and Environmental Sciences, Elsevier., 2021.

Creed, I. F., McKnight, D. M., Pellerin, B. A., Green, M. B., Bergamaschi, B. A., Aiken, G. R., Burns, D. A., Findlay, S. E. G., Shanley, J. B., Striegl, R. G., Aulenbach, B. T., Clow, D. W., Laudon, H., McGlynn, B. L., McGuire, K. J., Smith, R. A. and Stackpoole, S. M.: The river as a chemostat: fresh perspectives on dissolved organic matter flowing down the river 480 continuum, edited by R. Smith, Canadian Journal of Fisheries and Aquatic Sciences, 72(8), 1272-1285, doi:10.1139/cjfas2014-0400, 2015.

Dupas, R., Causse, J., Jaffrezic, A., Aquilina, L. and Durand, P.: Flowpath controls on high-spatial-resolution water-chemistry profiles in headwater streams, Hydrological Processes, doi:10.1002/hyp.14247, 2021.

Futter, M. N., Butterfield, D., Cosby, B. J., Dillon, P. J., Wade, A. J. and Whitehead, P. G.: Modeling the mechanisms that

485 control in-stream dissolved organic carbon dynamics in upland and forested catchments, Water Resources Research, 43(2), doi:10.1029/2006wr004960, 2007.

Gómez-Gener, L., Lupon, A., Laudon, H. and Sponseller, R. A.: Drought alters the biogeochemistry of boreal stream networks, Nature communications, 11(1), 1-11, 2020.

Grabs, T., Bishop, K., Laudon, H., Lyon, S. W. and Seibert, J.: Riparian zone hydrology and soil water total organic carbon

490 (TOC): implications for spatial variability and upscaling of lateral riparian TOC exports, Biogeosciences, 9(10), 3901-3916, 2012.

Hale, R. L. and Godsey, S. E.: Dynamic stream network intermittence explains emergent dissolved organic carbon chemostasis in headwaters, Hydrological Processes, doi:10.1002/hyp.13455, 2019.

Heidbüchel, I., Yang, J., Musolff, A., Troch, P., Ferré, T. and Fleckenstein, J. H.: On the shape of forward transit time 495 distributions in low-order catchments, Hydrology and Earth System Sciences, 24(6), 2895-2920, doi:10.5194/hess-24-28952020, 2020.

Hotchkiss, E., Hall Jr, R., Sponseller, R., Butman, D., Klaminder, J., Laudon, H., Rosvall, M. and Karlsson, J.: Sources of and processes controlling CO 2 emissions change with the size of streams and rivers, Nature Geoscience, 8(9), 696, 2015.

Jencso, K. G., McGlynn, B. L., Gooseff, M. N., Wondzell, S. M., Bencala, K. E. and Marshall, L. A.: Hydrologic connectivity

500 between landscapes and streams: Transferring reach-and plot-scale understanding to the catchment scale, Water Resources Research, 45(4), 2009.

Jencso, K. G., McGlynn, B. L., Gooseff, M. N., Bencala, K. E. and Wondzell, S. M.: Hillslope hydrologic connectivity controls riparian groundwater turnover: Implications of catchment structure for riparian buffering and stream water sources, Water Resources Research, 46(10), 2010.

505 Kiewiet, L., Freyberg, J. von and Meerveld, H. van: Spatiotemporal variability in hydrochemistry of shallow groundwater in a small pre-alpine catchment: the importance of landscape elements, Hydrological Processes, 2019.

Klaus, J. and Jackson, C. R.: Interflow Is Not Binary: A Continuous Shallow Perched Layer Does Not Imply Continuous Connectivity, Water Resources Research, 54(9), 5921-5932, 2018.

Kothawala, D. N., Ji, X., Laudon, H., Ågren, A. M., Futter, M. N., Köhler, S. J. and Tranvik, L. J.: The relative influence of

510 land cover, hydrology, and in-stream processing on the composition of dissolved organic matter in boreal streams, Journal of Geophysical Research: Biogeosciences, 120(8), 1491-1505, doi:10.1002/2015jg002946, 2015.

Kritzberg, E. S., Hasselquist, E. M., Škerlep, M., Löfgren, S., Olsson, O., Stadmark, J., Valinia, S., Hansson, L.-A. and Laudon, H.: Browning of freshwaters: Consequences to ecosystem services, underlying drivers, and potential mitigation measures, Ambio, 49(2), 375-390, 2020.

515 Laudon, H. and Ottosson Löfvenius, M.: Adding snow to the picture-providing complementary winter precipitation data to the Krycklan catchment study database, Hydrological Processes, 30(13), 2413-2416, 2016.

Laudon, H., Seibert, J., Köhler, S. and Bishop, K.: Hydrological flow paths during snowmelt: Congruence between hydrometric measurements and oxygen 18 in meltwater, soil water, and runoff, Water resources research, 40(3), 2004.

Laudon, H., Taberman, I., Ågren, A., Futter, M., Ottosson-Löfvenius, M. and Bishop, K.: The Krycklan Catchment Study—a 520 flagship infrastructure for hydrology, biogeochemistry, and climate research in the boreal landscape, Water Resources Research, 49(10), 7154-7158, 2013. 
Laudon, H., Hasselquist, E. M., Peichl, M., Lindgren, K., Sponseller, R., Lidman, F., Kuglerová, L., Hasselquist, N. J., Bishop, K., Nilsson, M. B. and Ågren, A. M.: Northern landscapes in transition: Evidence, approach and ways forward using the Krycklan Catchment Study, Hydrological Processes, 35(4), doi:10.1002/hyp.14170, 2021.

525 Leach, J., Lidberg, W., Kuglerová, L., Peralta-Tapia, A., Ågren, A. and Laudon, H.: Evaluating topography-based predictions of shallow lateral groundwater discharge zones for a boreal lake-stream system, Water Resources Research, 53(7), 5420-5437, 2017.

Leach, J. A. and Laudon, H.: Headwater lakes and their influence on downstream discharge, Limnology and Oceanography Letters, 4(4), 105-112, 2019.

530 Ledesma, J. L., Grabs, T., Bishop, K. H., Schiff, S. L. and Köhler, S. J.: Potential for long-term transfer of dissolved organic carbon from riparian zones to streams in boreal catchments, Global change biology, 21(8), 2963-2979, 2015.

Ledesma, J. L., Futter, M. N., Blackburn, M., Lidman, F., Grabs, T., Sponseller, R. A., Laudon, H., Bishop, K. H. and Köhler, S. J.: Towards an improved conceptualization of riparian zones in boreal forest headwaters, Ecosystems, 21(2), 297-315, 2018.

Li, L., Sullivan, P. L., Benettin, P., Cirpka, O. A., Bishop, K., Brantley, S. L., Knapp, J. L. A., Meerveld, I., Rinaldo, A., 535 Seibert, J., Wen, H. and Kirchner, J. W.: Toward catchment hydro-biogeochemical theories, WIREs Water, 8(1), doi:10.1002/wat2.1495, 2020.

Lidberg, W., Nilsson, M. and Ågren, A.: Using machine learning to generate high-resolution wet area maps for planning forest management: A study in a boreal forest landscape, Ambio, 1-12, 2019.

Lupon, A., Denfeld, B. A., Laudon, H., Leach, J., Karlsson, J. and Sponseller, R. A.: Groundwater inflows control patterns and sources of greenhouse gas emissions from streams, Limnology and Oceanography, 2019.

Lyon, S. W., Laudon, H., Seibert, J., Mörth, M., Tetzlaff, D. and Bishop, K. H.: Controls on snowmelt water mean transit times in northern boreal catchments, Hydrological processes, 24(12), 1672-1684, 2010.

McGlynn, B. L. and McDonnell, J. J.: Quantifying the relative contributions of riparian and hillslope zones to catchment runoff, Water Resources Research, 39(11), 2003.

545 Mineau, M. M., Wollheim, W. M., Buffam, I., Findlay, S. E. G., Hall, R. O., Hotchkiss, E. R., Koenig, L. E., McDowell, W. H. and Parr, T. B.: Dissolved organic carbon uptake in streams: A review and assessment of reach-scale measurements, Journal of Geophysical Research: Biogeosciences, 121(8), 2019-2029, doi:10.1002/2015jg003204, 2016.

Ploum, S.: Groundwater connections between the boreal landscape and its headwater streams: the role of discrete riparian inflow points (DRIPs), Department of Forest Ecology and Management, Swedish University of Agricultural Sciences. [online] Available from: http://urn.kb.se/resolve?urn=urn:nbn:se:slu:epsilon-p-111341, 2021.

Ploum, S. W., Leach, J. A., Kuglerová, L. and Laudon, H.: Thermal detection of discrete riparian inflow points (DRIPs) during contrasting hydrological events, Hydrological Processes, 32(19), 3049-3050, 2018.

Ploum, S. W., Laudon, H., Peralta-Tapia, A. and Kuglerová, L.: Are dissolved organic carbon concentrations in riparian groundwater linked to hydrological pathways in the boreal forest?, Hydrology and Earth System Sciences, 24(4), 1709-1720, 2020.

Raymond, P. A., Saiers, J. E. and Sobczak, W. V.: Hydrological and biogeochemical controls on watershed dissolved organic matter transport: Pulse-shunt concept, Ecology, 97(1), 5-16, 2016.

Rinderer, M., Meerveld, H. J. and McGlynn, B. L.: From Points to Patterns: Using Groundwater Time Series Clustering to Investigate Subsurface Hydrological Connectivity and Runoff Source Area Dynamics, Water Resources Research, 55(7), 5784-5806, doi:10.1029/2018wr023886, 2019.

Rocher-Ros, G., Sponseller, R. A., Lidberg, W., Mörth, C.-M. and Giesler, R.: Landscape process domains drive patterns of CO2 evasion from river networks, Limnology and Oceanography Letters, 2019.

Rosenberry, D. O., Briggs, M. A., Delin, G. and Hare, D. K.: Combined use of thermal methods and seepage meters to efficiently locate, quantify, and monitor focused groundwater discharge to a sand-bed stream, Water Resources Research, 52(6), 4486-4503, 2016.

Seibert, J., Grabs, T., Köhler, S., Laudon, H., Winterdahl, M. and Bishop, K.: Linking soil-and stream-water chemistry based on a Riparian Flow-Concentration Integration Model, Hydrology and earth system sciences, 13(12), 2287-2297, 2009. 
Selker, J., Giesen, N. van de, Westhoff, M., Luxemburg, W. and Parlange, M. B.: Fiber optics opens window on stream dynamics, Geophysical Research Letters, 33(24), 2006.

570 Seybold, E. and McGlynn, B.: Hydrologic and biogeochemical drivers of dissolved organic carbon and nitrate uptake in a headwater stream network, Biogeochemistry, 138(1), 23-48, doi:10.1007/s10533-018-0426-1, 2018.

Talbot, C. J., Bennett, E. M., Cassell, K., Hanes, D. M., Minor, E. C., Paerl, H., Raymond, P. A., Vargas, R., Vidon, P. G., Wollheim, W. and Xenopoulos, M. A.: The impact of flooding on aquatic ecosystem services, Biogeochemistry, 141(3), 439461, doi:10.1007/s10533-018-0449-7, 2018.

575 Tiwari, T., Laudon, H., Beven, K. and Ågren, A. M.: Downstream changes in DOC: Inferring contributions in the face of model uncertainties, Water Resources Research, 50(1), 514-525, doi:10.1002/2013wr014275, 2014.

Vidon, P. G.: Not all riparian zones are wetlands: Understanding the limitation of the "wetland bias" problem, Hydrological Processes, 31(11), 2125-2127, 2017.

Wallin, M. B., Grabs, T., Buffam, I., Laudon, H., Ågren, A., Öquist, M. G. and Bishop, K.: Evasion of CO 2 from streams-

580 The dominant component of the carbon export through the aquatic conduit in a boreal landscape, Global Change Biology, 19(3), 785-797, 2013.

Werner, B. J., Musolff, A., Lechtenfeld, O. J., Rooij, G. H. de, Oosterwoud, M. R. and Fleckenstein, J. H.: High-frequency measurements of dissolved organic carbon quantity and quality in a headwater catchment, Biogeosciences Discussions, 2019.

Wollheim, W. M., Stewart, R. J., Aiken, G. R., Butler, K. D., Morse, N. B. and Salisbury, J.: Removal of terrestrial DOC in

585 aquatic ecosystems of a temperate river network, Geophysical Research Letters, 42(16), 6671-6679, doi:10.1002/2015gl064647, 2015.

Wollheim, W. M., Bernal, S., Burns, D. A., Czuba, J. A., Driscoll, C. T., Hansen, A. T., Hensley, R. T., Hosen, J. D., Inamdar, S., Kaushal, S. S., Koenig, L. E., Lu, Y. H., Marzadri, A., Raymond, P. A., Scott, D., Stewart, R. J., Vidon, P. G. and Wohl, E.: River network saturation concept: factors influencing the balance of biogeochemical supply and demand of river networks,

Biogeochemistry, 141(3), 503-521, doi:10.1007/s10533-018-0488-0, 2018.

Zambrano-Bigiarini, M.: Package 'hydroGOF, Goodness-of-fit Functions for Comparison of Simulated and Observed, 2020. 